\title{
Cataract-ataxia-deafness syndrome
}

INSERM

\section{Source}

INSERM. (1999). Orphanet: an online rare disease and orphan drug data base. Cataractataxia-deafness syndrome. ORPHA:1368

Cataract-ataxia-deafness syndrome is characterised by mild intellectual deficit, congenital cataract, progressive sensorineural deafness and ataxia. It has been described in two sisters. The inheritance is likely to be autosomal recessive. 